\section{CLINICAL EVOLUTION AND ETIOLOGY IN CHILDREN HOSPITALIZED WITH COMMUNITY-ACQUIRED PNEUMONIA}

T. Fonseca, C. Nascimento-Carvalho

Background

Community-acquired pneumonia (CAP) remains an important cause of morbidity and mortality in children. Etiologic diagnosis is rarely established because lower respiratory tract specimens are difficult to obtain. Viral infection, however, is the most common one. Thus, empirical antibiotic therapy is probably over used. The aim of this study was to describe and compare the evolution and outcome in children hospitalized with CAP categorized in subgroups carefully defined by probable etiology.

\section{Methods}

This was a prospective study conducted at the Emergency Room of a school hospital in Northeast of Brazil, from 2003 to 2005 . Children under-5 years diagnosed by the pediatrician on duty with CAP were enrolled based upon fulfillment of the following criteria: 1) respiratory complaints plus 2) fever or difficulty breathing plus 3) pulmonary infiltrates on the CXR taken at admission. Exclusion criteria included refusal to give informed consent, children born to an HIV infected woman, chronic lung disease except asthma, other concomitant infectious disease, immunodeficiency, when probable etiologic diagnosis was not made and chest radiograph was not diagnosed with pneumonia by a radiologist (Figure 1). On recruitment, clinical data were collected as well as biologic samples, used to investigate 18 etiologic pathogens: eleven viruses and 7 bacteria. All CXR were read by a pediatric radiologist and daily evolution data were collected from medical charts by a researcher both blinded to patients' clinical data. The cases were classified as sole viral, atypical bacterial or typical bacterial infection or viralbacterial infection. The study was approved by the Ethics Committee of the Federa University of Bahia.

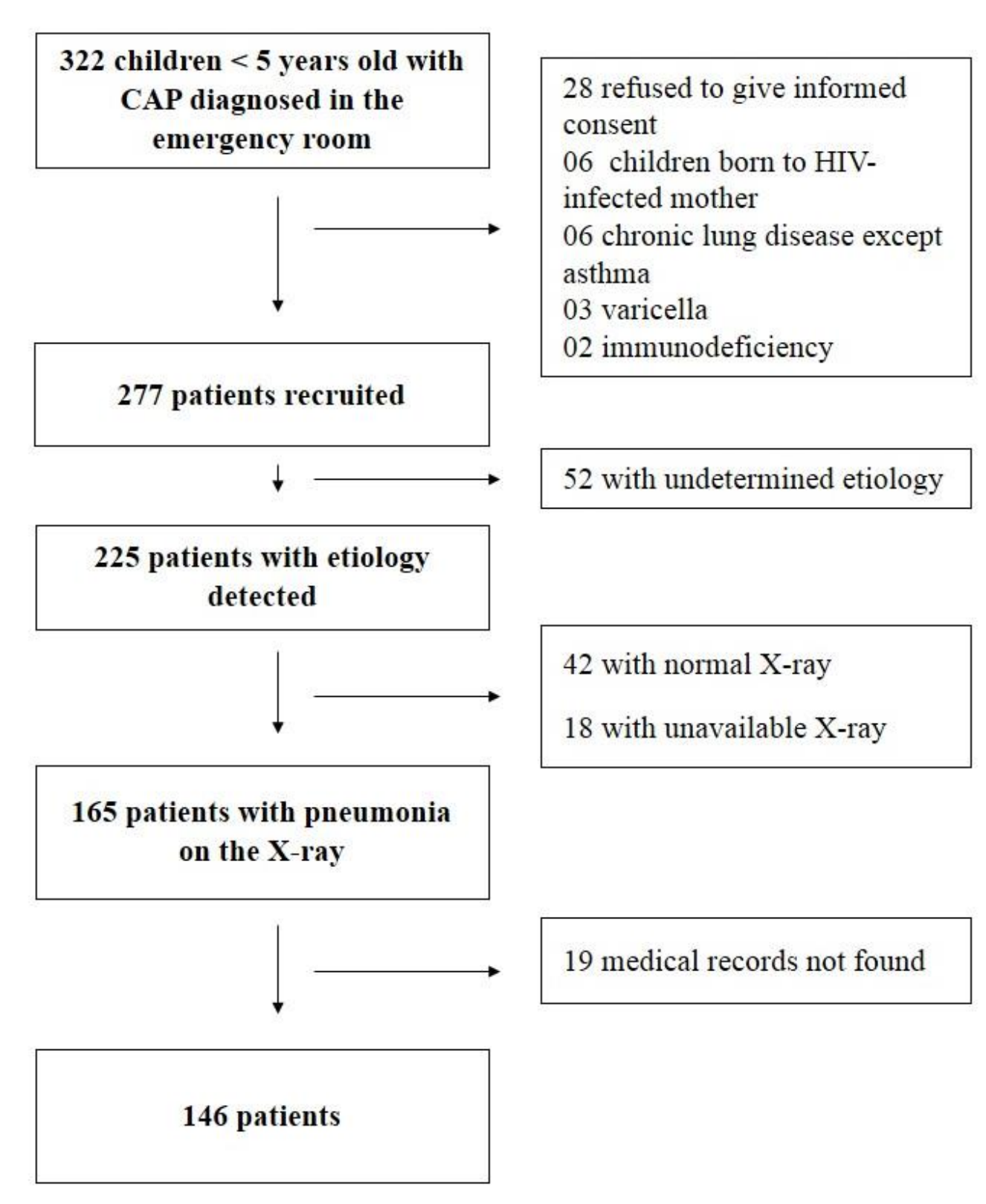

The median age was 19.2 (10.3-32.3; min 0.9 ; max 59) months and the length of hospital stay was 6 (4-9.8) days. There were $74(57.8 \%)$ boys. The most common symptoms on admission were cough, fever and difficulty breathing in all groups. The most common finds on physical exam on admission were tachypnea, crackles and chest indrawing. Table 1 shows evolution of these children categorized by probable etiology - no statistical difference was detected. All children received antibiotics for treatment at the discretion of the attending pediatrician that was blinded to etiologic investigation. Penicillins were chosen as first option in $85.2 \%$ of the cases, followed by the association of ceftriaxone and oxacillin $(3.9 \%)$ and erythromycin (3.1\%). Sixteen $(12.5 \%)$ patients had the antimicrobia spectrum changed also at the discretion of the attending pediatrician.

\begin{tabular}{|c|c|c|c|c|c|}
\hline \multirow{2}{*}{$\begin{array}{l}\text { Characteristics on } 3^{\text {rd }} \\
\text { day of treatment }\end{array}$} & \multirow{2}{*}{ All patients (128) } & \multicolumn{3}{|c|}{ Sole infection (82) } & \multirow{2}{*}{$\begin{array}{l}\text { Viral-bacterial } \\
\text { coinfection }(46\end{array}$} \\
\hline & & Typical bacteria (17) & Atypical bacteria (11) & Virus (54) & \\
\hline Fever & $23(18)$ & $4(23.5)$ & 0 & $8(14.8)$ & $11(23.9)$ \\
\hline Tachypnea & $53(41.4)$ & $6(35.3)$ & $3(27.3)$ & $20(37.0)$ & $24(52.2)$ \\
\hline Cough & $81 / 122(66.4)$ & $13(76.5)$ & 7 (63.6) & $32 / 50(64.0)$ & 29/44 (65.9) \\
\hline Difficulty breathing & $51 / 124(41.1)$ & 6/17 (37.9) & $4 / 10(40.0)$ & $22 / 53(41.5)$ & $19 / 45(42.2)$ \\
\hline Malaise & 9/121 (7.4) & $3 / 16(18.8)$ & $1(9.1)$ & $3 / 51(5.9)$ & $2 / 43(4.7)$ \\
\hline Chest indrawing & $16(12.5)$ & $2(11.8)$ & $3(27.3)$ & $7(13)$ & $4(8.7)$ \\
\hline Vomiting & $5 / 119(4.2)$ & $1(5.9)$ & 0/10 & $2 / 50(4.0)$ & $2 / 42(4.8)$ \\
\hline Thoracic recession & $7(5.5)$ & $1(5.9)$ & $1(9.1)$ & $5(9.3)$ & 0 \\
\hline Grunting & $1(0.8)$ & 0 & 0 & 0 & $1(2.2)$ \\
\hline $\begin{array}{l}\text { Length of hospital } \\
\text { stay (days) }\end{array}$ & $6(4 ; 9.75)$ & $5(3 ; 9.5)$ & $8(4 ; 13)$ & $7(5: 10)$ & $6(4 ; 8.25)$ \\
\hline
\end{tabular}

Twenty three patients (18.0\%) had fever on 3rd day of antibiotic therapy. No clinical difference was detected during evolution among the distinct etiological subgroups. Antibiotic change was associated with fever on 3rd day of treatment and was not associated with bacterial infection.

\section{Conclusions}

Antibiotic treatment is overused in children hospitalized with CAP, since sole viral infection is the probable cause of almost half of patients. These children evolve similarly, irrespective of the etiological agent and empirical therapy. Change in antibiotic therapy is not associated to bacterial infection, although is related to presence offever after $48 \mathrm{~h}$ of tratment onset.
Fig 1. Flow-chart to compose the study group

\section{Results}

One hundred and forty-six patients were initially selected for the study. All of them had probable etiology determined, Overall, $82(56.2 \%)$ patients had sole infection, out of which $17(20.7 \%), 11$ $(13.4 \%)$ and $54(65.9 \%)$ had typical bacterial atypical bacterial and viral infections, respectively (Figure 2). Forty-six patients $(31.5 \%)$ had viralbacterial co-infection and 18 (12.3\%) patients had viral-viral or bacterial-bacterial co-infection; these cases with viral-viral or bacterial-bacterial coinfection were excluded from analysis. Thus, the study group comprised 128 cases. The most frequent etiologic agents were RSV (10.9\%), rhinovirus $(10.2 \%)$, parainfluenza virus $(9.4 \%)$ and pneumococo $(9.4 \%)$. 